\title{
Word reading and picture naming in Italian
}

\author{
ELIZABETH BATES \\ University of California, San Diego, La Jolla, California \\ CRISTINA BURANI \\ Institute of Psychology, National Council of Research, Rome, Italy \\ and \\ SIMONA D'AMICO and LAURA BARCA \\ University of Rome "La Sapienza," Rome, Italy \\ and Institute of Psychology, National Council of Research, Rome, Italy
}

\begin{abstract}
Results from two separate norming studies of lexical access in Italian were merged, permitting a comparison of word-reading and picture-naming latencies and the factors that predict each one for an overlapping subsample of 128 common nouns. Factor analysis of shared lexical predictors yielded four latent variables: a frequency factor, a semantic factor, a length factor, and a final factor dominated by frication on the initial phoneme. Age of acquisition (AoA) loaded highly on the first two factors, suggesting that it can be split into separate sources of variance. Regression analyses using factor scores as predictors showed that word reading and picture naming are both influenced by the frequency/AoA factor. The semantics/AoA factor influenced only picture naming, whereas the length and frication factors influenced only word reading. Generalizability of these results to other languages is discussed, including potential effects of cross-language differences in orthographic transparency.
\end{abstract}

Word reading and picture naming are tasks with a long history in psycholinguistic research (Cattell, 1886), including studies comparing reaction times (RTs) in each modality for the same target words (Federmeier, 1999; Federmeier \& Kutas, 1999a, 1999b, 2001; Potter \& Faulconer, 1975; Potter, Kroll, Yachzel, Carpenter, \& Sherman, 1986). The present study falls within that well-established tradition, but it adds two new kinds of information.

First, we will directly compare the factors that influence word reading and picture naming (e.g., existence and relative magnitude of effects on RT from frequency, age of acquisition [AoA], and various semantic and phonological characteristics of target words). Modality comparisons of this kind can increase our understanding of the levels of processing involved in each task and the time required for processing at each level. Such comparisons have been conducted in the past, but they have concentrated on differences between object naming and either object decision or semantic classification (Humphreys, Lamote, \& LloydJones, 1995; Moore, Valentine, \& Turner, 1999; Morrison, Ellis, \& Quinlan, 1992) or on differences between word naming and lexical decision (Morrison \& Ellis, 1995, 2000).

The picture-naming portion of this project was supported by NIH Grant DC00216 to E.B. (Cross-Linguistic Studies of Aphasia). The word-reading portion was supported by the Institute of Psychology, $\mathrm{Na}$ tional Council of Research, Rome. The authors thank Lisa-Saskia Arduino for comments and suggestions and Anna Székely and Bob Buffington for technical assistance. Correspondence should be addressed to E. Bates, Center for Research in Language 0526, University of California, San Diego, La Jolla, CA 92093-0526(e-mail: bates@crl.ucsd.edu).
Second, we will compare word reading and picture naming in Italian, with implications for potential cross-language differences in lexical access. In contrast with English, which has a complex orthographic system involving many irregular forms, the Italian system of grapheme-to-phoneme correspondence is extremely transparent. In fact, word stress is the only aspect of pronunciation that cannot be predicted directly from the written form of the word. Hence, in principle, it should be easier to pass directly from graphemic input to oral pronunciationin Italian, with little or no reliance on semantic information (at least if words are presented in isolation). Although we will not present direct comparisons with English in this preliminary study, results will help to motivate future crosslinguistic studies of lexical access. Before proceeding, let us briefly consider the kinds of results that have emerged in previous studies of word reading versus picture naming, with implications for competing models of lexical access.

\section{LEXICAL ACCESS IN TWO MODALITIES}

All previous studies that have explored word reading and picture naming in sentence contexts have reported shorter latencies for word reading (at least in adults). Various proposals to account for this RT difference have been advanced. For example, Potter and Faulconer (1975) and Potter et al. (1986) suggested that picture naming requires obligatory lexical access, whereas word reading could (at least in principle) be accomplished without accessing the full semantic and grammatical representation of the word (both lemma and concept). However, word reading (also 
called word pronunciation, or visual word naming) has been used successfully in dozens of semantic and/or grammatical priming studies, suggesting that readers do access multiple levels of lexical representation while they are reading target words. Picture naming is used less often in priming paradigms, but the few studies that have used picture naming for this purpose have also reported robust effects of semantic and/or grammatical context (Bentrovato, Devescovi, D'Amico, \& Bates, 1999; Federmeier \& Bates, 1997; Jacobsen, 1999; Lu et al., 2000; Wicha, Bates, Hernandez, Reyes, \& Gavaldón de Barreto, 1997), including a recent study showing effects of sentence context on picture naming from 3 to 87 years of age (Roe et al., 2000).

In the studies that have investigated single-word reading and single-picture naming outside of a sentence context, effects of lexical variables, such as word frequency, familiarity, and/or AoA, have been reported for both visual word naming and picture naming, although the locus of these effects is still controversial (Barry, Morrison, \& Ellis, 1997; Brysbaert, Lange, \& van Wijnendaele, 2000; Carroll \& White, 1973a, 1973b; Ellis \& Morrison, 1998; Gerhand \& Barry, 1998; Gilhooly \& Logie, 1981; Morrison, Chappell, \& Ellis, 1997; Morrison \& Ellis, 1995, 2000; Morrison et al., 1992). With regard to effects of semantic factors, such as imageability or concreteness, most models of object and/or picture naming assume that perceptual information and conceptual information are the major factors driving the activation of phonological word forms (e.g., Humphreys et al., 1995). By contrast, most models of word reading include at least two distinct sources of phonological activation: orthographic and semantic (see, e.g., Coltheart, Curtis, Atkins, \& Haller, 1993; Plaut, McClelland, Seidenberg, \& Patterson, 1996). Indeed, the effects of semantic variables on single-word reading are still a matter of debate (see Balota, Ferraro, \& Connor, 1991).

Recent studies of word reading in English have shown that imageability effects are normally not observed for short, regular/consistent words; instead, the primary influence of imageability is on low-frequency exception words (Cortese, Simpson, \& Woolsey, 1997; Strain, Patterson, \& Seidenberg, 1995; Zevin \& Balota, 2000). These results suggest that the semantic system is recruited only when the speaker finds it difficult to generate a pronunciation by relying on the orthography-to-phonologysystem. Studies of word reading in Italian are particularly interesting in this regard, because of the highly transparent nature of Italian orthography. In fact, studies of Italian word pronunciation have reported lexical effects, such as frequency, morphological constituency, and semantic priming for words (Burani, Marcolini, \& Stella, 2000; Colombo, 1992; Colombo \& Tabossi, 1992; Tabossi \& Laghi, 1992) and for pseudowords (Burani, Dovetto, Spuntarelli, \& Thornton, 1999; Burani \& Laudanna, in press; Burani et al., 2000; Job, Peressotti, \& Cusinato, 1998). So, it is already clear that Italians do pass through the lexicon during word reading, at least when list composition allows lexical effects to manifest themselves. However, we can offer the more conservative hypothesis that reliance on lexical reading may be weak for Italian relative to languages with deeper orthographies, such as English (Arduino \& Burani, 2000; Brysbaert et al., 2000; Frost, 1994; Frost, Katz, \& Bentin, 1987). Semantic effects, if any, might be even more reduced relative to English (Zevin \& Balota, 2000). In this regard, a recent neural imaging study by Paulesu et al. (2000) compared word reading in monolingual speakers of English versus Italian and found distinct patterns of activation. In Italian, word reading elicited activation primarily in superior temporal regions, which the authors attribute to phonemic processing. In English, the corresponding words (matched to Italian in length and complexity) elicited greater activation in frontal and inferior temporal sites, which the authors attribute to word retrieval. Regardless of how one chooses to interpret these frontal-temporal differences, the Paulesu et al. results provide support for the hypothesis that word-reading processes for Italian may differ from the processes that have been described to date in the very large literature on word reading in English.

One of the major controversies in this field revolves around the need for an amodal lexical level that mediates the relationship between meaning (conceptual content) and word form (phonological and/or orthographic). In some models based on reading and/or visual lexical decision, word recognition is defined as the moment at which this amodal level is activated (see Balota et al., 1991, for a discussion). Conversely, in some models of word production based on picture naming, lexical selection takes place from an array of amodal lexical representations (or lemmas) that are fully or partially compatible with the perceptual and conceptual input (Levelt, Roelofs, \& Meyer, 1999). Within such frameworks, effects of frequency and morphological composition on word activation are generally assumed to apply at this amodal lexical level. A markedly different approach can be found in an extensive review of the picture-naming literature by Johnson, Paivio, and Clark (1996). Johnson et al. argue in favor of the dual coding hypothesis, an approach in which lexical representation and processing involve a direct progression from meaning to sound, with no amodal stage. They review effects of predictor variables that are presumed to apply at three points during the naming process: (1) stimulus decoding and object recognition (affected by perceptual and conceptual variables), (2) selection of a unique sound pattern that corresponds to object meaning (affected by word characteristics, such as frequency, familiarity, and AoA, as well as characteristics of the lexical neighborhood), and (3) motor output (where factors such as length and the nature of the initial phoneme may apply).

A direct comparison of the factors that influence word reading and picture naming will help to clarify some of the empirical differences that separate the respective word-reading and picture-naming literatures, moving the field closer to a resolution of these competing views. We will compare RT results for word reading and picture naming in Italian-speaking adults, on the basis of 128 overlapping items (all common nouns) from two separate 
norming studies in the Italian language, each with a large database of information about the target words, including various ratings taken from separate samples of participants. The picture-naming data are drawn from the Italian component of a large international picture-naming norming study involving 520 object pictures, 50 participants per language (Bates et al., 2000; see also D'Amico, Devescovi, \& Bates, 2001). The word-reading data are drawn from a norming study of word reading in Italian, involving 516 common nouns and 30 participants. These data are part of a larger study in which normative data for various lexical and sublexical variables were collected (from 44 participants for each variable), for 626 Italian simplex nouns (Barca, Burani, \& Arduino, 2000; Burani, Barca, \& Arduino, in press).

On the basis of our previous findings for word reading in Italian, we expect to find lexical effects (e.g., frequency) and word form effects (e.g., length), which may apply in the absence of a contribution from semantic variables (e.g., imageability, concreteness). By contrast, picture naming should be heavily influenced by both semantic and lexical factors. These results for Italian serve as the motivation for a larger study (now in progress) comparing word reading, auditory word repetition, and picture naming for the same (translation-equivalent) items in Italian, English, and Chinese.

\section{METHOD}

\section{Word Reading}

Participants. The participants in the reading study were 30 university students (15 male, 15 female) between 20 and 30 years of age. All were native speakers of Italian. Some were volunteers; others were paid small sums for their participation.

Materials. The materials employed in this report were based on results for a large reading-time study (Barca et al., 2000) of 516 simple Italian nouns (morphologically uninflected nouns, four to nine letters in length, with a frequency between 1 and 2,253 based on a written corpus of 1,500,000 words; Istituto di Linguistica Computazionale del CNR di Pisa, 1989. These data are part of a larger study in which normative data for various lexical and sublexical variables were collected (from 44 participants for each variable), for 626 Italian simplex nouns (Barca et al., 2000; Burani et al., in press).

In the analyses presented below, we will restrict our attention to a subset of 128 words in the word-reading study that overlap with items in the picture-naming study (described below). Although the orthography of Italian is highly regular and transparent, there is some irregularity, or at least less predictability by rule, in the assignment of lexical stress. In this subset, of the 128 words, 60 were bisyllables, 60 had three syllables, and 8 had four syllables. Ten of the words with three to four syllables had stress on the antepenultimate syllable, deviating from the default (higher probability) penultimatestress pattern for Italian. The larger list within which these 128 words were presented included $44 \%$ bisyllabic words with predictable stress on the penultimate syllable and 56\% three- to foursyllable words for which lexical stress is less predictable by rule. Moreover, $15 \%$ of the words on the total list had the less frequent pattern of stress on the antepenultimate syllable. These constraints would favor lexical look-up for stress assignment, thus allowing lexicalsemantic effects, if any, to manifest themselves in reading (see Colombo \& Tabossi, 1992; Tabossi \& Laghi, 1992).

Procedure. The participants were tested individually in a quiet room. They were asked to read aloud a series of words that would ap- pear on the computer screen in front of them. The words were divided into blocks and were presented in a single session. The order of words within blocks was individually randomized. The order of block presentation was also randomized. Before beginning the task, the participants read printed instructions, in which they were asked to respond as quickly as possible but to avoid making mistakes. RTs from word onset to the beginning of each vocalization were collected by a voice key connected to the computer, within the MEL Professional 2.0 experimental control shell. A microphone was attached to the voice key and to a tape recorder for recording the session. The experimenter registered all the stimuli incorrectly pronounced, and those were eliminated from subsequent analyses.

The stimuli appeared in uppercase letters in the center of the computer screen, preceded by a fixation point $(400 \mathrm{msec})$. They stayed on the computer screen for a maximum of $1 \mathrm{sec}(1,000 \mathrm{msec})$. If the participant did not produce any answer within that time, the feedback "fuori tempo" ("out of time") appeared on the screen. The experiment was preceded by a brief practice session to familiarize the participants with the task; items in the practice session did not occur in the main experiment.

Predictor variables for word reading. All of the words in the reading database were coded to reflect the following predictor variables, selected among those that have been shown to affect wordnaming times and accuracy at the different levels (or components): $A o A$, defined as the estimated age at which the word and its meaning were first learned, either in the auditory modality or in the written modality (Carroll \& White, 1973a, 1973b; Morrison et al., 1997); familiarity, defined as the estimated frequency of occurrence of the word, in written or spoken form, in the raters' own daily lives or the daily lives of other people like themselves (Connine, Mullennix, Shernoff, \& Yelen, 1990; Gernsbacher, 1984; Noble, 1953); imageability, defined as the ease and speed with which the target word evokes a mental image (a visual representation, a sound, or any other sensory experience; Paivio, Yuille, \& Madigan, 1968); and concreteness, defined as a property of words referring to objects, animate beings, actions, or materials that can be experienced directly by the senses (Paivio et al., 1968).

Values for these four variables were gathered in subjective ratings (on a 1-7 scale) by 176 students ( 22 male and 22 female, for each variable). All raters were native speakers of Italian between 20 and 30 years of age and were students at one of several universities in the Rome area. None of the students in the reading study had participated in these ratings. The instructions used for the different ratings are reported in Appendix A.

In addition to these ratings, the following measures were taken: written adult word frequencies, taken from the CNR Institute of Computational Linguistics (1989) database, based on a corpus of $1,500,000$ words in contemporary written Italian texts; written child word frequencies, taken from the Lessico Elementare (Elementary Lexicon) by Marconi, Ott, Pesenti, Ratti, and Tavella (1993) (These norms are based on materials written by adults for children and on writings by children. The corpus includes 500,000 word tokens adopted from readers, fairy tales, school newspapers, comic books, and textbooks written for children between the first and fifth grades; another 500,000 tokens are taken from essays written by first- to fifthgrade children. Of the various indices available, our word-reading study used absolute word frequency [unweighted tokens of the citation form from the entire corpus]); spoken adult word frequencies, taken from the Lessico di dell'italiano parlato (Lexical Frequencies in Spoken Italian) by De Mauro, Mancini, Vedovelli, and Voghera (1993) based on a corpus of 500,000 words from samples of contemporary spoken Italian (our reading study used the frequency of the singular word form); number of orthographic neighbors, or density, defined as the number of words that can be obtained by substituting one letter at a time within the target (Coltheart, Davelaar, Jonasson, \& Besner, 1977; for a review of effects of orthographic density on recognition of written words, see Andrews, 1997) (density 
values for these Italian words were taken from Baldi and Traficante, 2000 , adjusted to exclude word neighbors that are highly unfamiliar); and word length in letters, based on a simple orthographic count (for the investigation of orthographic word length effects on reading, see, e.g., Burani et al., 2000, and Weekes, 1997, for Italian and English, respectively).

\section{Picture Naming}

Participants. For comparison with performance in the reading study, we made use of data for 50 adult native speakers of Italian, taken from the Center for Research in Language international picturenaming (CRL-IPN) study (Bates et al., 2000; see also D'Amico et al., 2001). All participants were university students who volunteered or were paid a small sum for their participation.

Materials. Picture stimuli for object naming were black-andwhite line drawings of common objects from various sources, including 174 pictures from the original set by Snodgrass and Vanderwart (1980). (For further details, see Bates et al., 2000.) All stimuli were scanned and stored digitally for presentation within the PsyScope experimental control shell, in 10 different randomized orders.

Procedure. The digitized picture images were set in black outline on a white background and were presented on the monitor of a Macintosh laptop computer. The participant wore headphones with a sensitive built-in microphone (adjusted to optimal distance from the participant's mouth) that were connected to the Carnegie Mellon button box, a measuring device with 1-msec resolution design for use with Macintosh computers. RTs were collected by a voice key using the CMU button box, which was connected to the computer. The PsyScope Experimental Shell, a program developed to administer experimental presentation (presentation of stimuli, storing data, recording time, response, etc.) was used (Cohen, MacWhinney, Flatt, \& Provost, 1993).

Each participant was tested individually in a quiet room, in a single session. The participants were instructed to name the pictures with the first name that came to mind, as quickly as possible without making a mistake. They were urged to speak clearly, to name each picture with a single word if possible, and not to emit any other sounds (no clearing of the throat, no preparatory sounds such as "ãuhmmmä," no articles before the noun). To familiarize them with the procedure, they were given a practice period with pictures depicting geometric forms (circle, triangle, etc.) that did not appear in the main experiment. On each trial, the target picture remained on the screen for a maximum of $5 \mathrm{sec}(5,000 \mathrm{msec})$. The picture disappeared from the screen as soon as a vocal response was registered by the voice key; if there was no response, the picture disappeared at the end of the 5,000-msec window. The participants were randomly assigned to 1 of 10 random orders of picture presentation. During the session, the experimenter held a list of stimuli corresponding to the random order for each participant, on which the experimenter wrote the participant's response (if it differed from the expected name) and indicated any failures to respond or other artifacts.

Scoring. The target name for each picture was determined empirically, in two steps. First, the data were subjected to error coding to determine which responses could be retained for both naming and RT analyses. Responses were eliminated if there were failures to respond, if there were RT artifacts (coughs, hesitations, false starts, or prenominal verbalization such as "that's a ball"), or if the participant did produce a name but it failed to register with the voice key. On the basis of the remaining trials, the target name was defined as the dominant response (i.e., the name that was used by the largest number of participants). Various lexical codings were given for alternatives to the dominant response (morphological variants, synonyms, other). For present purposes, we will restrict our analyses to RTs for those trials on which the participants produced the dominant response, corresponding to the target words that were also used in the reading-time study.

In addition to some of the variables outlined above for the readingtime study, the following variables were used in the picture-naming study: word length in syllables; presence/absence of a fricative or affricate in the initial consonant $(0=$ no fricative or affricate; $1=$ fricative or affricate), included because this variable has been reported to influence the time required for a response to register on the voice key (for fricatives and affricates being slower in triggering the voice key; see, e.g., Treiman, Mullennix, Bijeljac-Babic, \& RichmondWelty, 1995, Part 2); written child word frequencies, from the same source adopted for the word-reading study (Marconi et al.,1993) (Whereas the reading study had taken the absolute frequency of the citation form across the entire corpus as the basis for these counts, the picture-naming study had adopted an adjusted frequency measure that took into account the distribution of the word across various corpora within the Marconi et al. database. In this comparative study, we will use both indices, for both modalities); spoken adult word frequencies, taken from the same source adopted for the wordreading study (De Mauro et al., 1993) (Whereas the reading study had used the frequency of the singular word form, the picture-naming study had adopted the cumulative frequency of both singular and plural. In this comparative study, we will use both indices, for both modalities.); objective measures of AoA, derived from published norms for the Italian version of the MacArthur Communicative Inventory (Caselli \& Casadio, 1995; cf. Fenson et al., 1994), a parentalreport form that provides valid and reliable data about lexical development in Italian infants from 8 to 30 months (The MacArthur CDI is based on concurrent parent report of vocabulary development in very large samples of children, collected in a recognition-memory format with a large checklist of words that are likely to be acquired between 8 and 30 months. For our purposes here, the CDI yields a simple 3-point scale: 1 = words acquired [on average] between 8 and 16 months; 2 = words acquired [on average] between 17 and 30 months; $3=$ words that are not acquired in infancy [ $>30$ months]); and subjective ratings of AoA, for 520 target words from a sample of 37 college students, based on a 9-point scale that has been used in other studies of English (see, e.g., Carroll \& White, 1973a, 1973b), including other studies within the international picture-naming project (Bates et al., 2000; the instructions and the scale are reported in Appendix B).

\section{RESULTS AND DISCUSSION}

All of the analyses presented below were based on the 128 items that overlapped between the word-reading and picture-naming studies and were conducted over items. Naming latencies for words in each modality were combined in a single database, together with the predictor variables from each study. All word-frequency indices were based on $\log$ transforms. The full list of items is in Appendix C, which also includes mean latencies for each item, in each modality (raw RTs averaged over participants), as well as $z$ score RTs for each item (based on the mean over items). The $z$ scores are included to facilitate cross-modality comparisons.

\section{Comparison of Dependent Variables}

Table 1 summarizes descriptive statistics for naming latencies in each modality. Not surprisingly, RTs for picture naming were substantially longer than RTs for word reading.

Table 1

Descriptive Statistics in Milliseconds for Word-Reading and Picture-Naming Reaction Times

\begin{tabular}{lrrcr}
\hline & $M$ & $S D$ & Minimum & Maximum \\
\hline Word reading & 525 & 26 & 474 & 592 \\
Picture naming & 1,036 & 198 & 694 & 1,580 \\
\hline
\end{tabular}


We had anticipated that the correlation between modalities for naming latencies would be relatively low, but we assumed that the 128 words would share at least some degree of item difficulty across modalities, resulting in RT correlations somewhere in the range of +.30 to +.40 . To our surprise, the correlation was virtually zero $(r=+.03$, n.s. $)$.

It is reasonable to ask whether the surprisingly low correlation between word-reading and picture-naming latencies is peculiar to the particular participants in either study or both studies and/or to the different lists in which these 128 words were embedded. Toward this end, we compared results of the present study with reading-time results for another 50 Italian-speaking college students, as part of a cross-modality study that is currently underway using all 520 of the words that emerged as the target names in our international picture-naming project (D'Amico et al., 2001).

First, we correlated word-reading times for our 128 words in the present study (assessed within the larger list used by Barca et al., 2000) with word-reading times for the same 128 words in the new study (assessed within the larger list of 520 picture names from Bates et al., 2000) and obtained a product-moment correlation of $+.64(p<$ $.0001)$. This correlation is of course highly significant, although it is not as high as we might expect given the similarity in tasks, which means (among other things) that the respective lists in which our 128 target words were embedded did affect RTs. For example, the 520 target words from the picture-naming study were longer, on average, than the words in the reading-time study, including a small proportion of target names for pictures that were morphologically complex (compounds or multiword phrases, such as macchina da scrivere for typewriter). Hence, list composition could contribute to differences between these two experiments, even though the 128 target words for the present study were the same in each modality.

Second, we calculated the correlation between picturenaming times (from the present study) and reading times (from the new study) for these 128 words. In this case, the modality comparison takes place within exactly the same list of 520 words. Nevertheless, the correlation between picture naming and word reading was still very low and nonsignificant ( $r=+.09$, n.s.). Hence, this constitutes a replication of the weak relationship between picture-naming and reading times uncovered in the present study, at least for these 128 items. It will be important to determine whether this result generalizes over different sets of items in different languages - an issue that we are currently exploring within the international picture-naming study.

\section{Correlations Among Predictors}

Table 2 summarizes correlations of word-reading and picture-naming latencies with each other and with all of the predictor variables described in the introduction (a total of 15). Briefly summarized, the various measures of frequency, familiarity, and subjective AoA seem to have an effect on both picture naming and word reading, in the usual directions. RTs in both modalities are also significantly slower (in the raw correlations, but see below) when
Table 2

Correlations of Word-Reading (WR) and Picture-Naming (PN) Reaction Times (RTs) With Each Other and With 15 Lexical Predictors

\begin{tabular}{lcc}
\hline \multicolumn{1}{c}{ Variable } & RT-WR & RT-PN \\
\hline RT-PN & .03 & \\
Subjective adult AoA (WR) & $.22^{* *}$ & $.39 * *$ \\
Objective AoA & $.12 \sim$ & $.21^{* *}$ \\
Subjective adult A0A (PN) & $.25^{* *}$ & $.44 * * *$ \\
Familiarity ratings & $-.22^{* *}$ & $-.37 * * *$ \\
Written adult frequencies & $-.33^{* *}$ & $-.34 * * *$ \\
Spoken adult frequencies & & \\
$\quad$ WR & $-.24 * *$ & $-.32^{* * *} *$ \\
PN & $-.26^{* *}$ & $-.30^{* * *}$ \\
Written child frequencies & $-.43^{* * *}$ & $-.30^{* * *}$ \\
$\quad$ WR & $-.42^{* * *}$ & $-.31^{* * *}$ \\
$\quad$ PN & $-.38^{* * *}$ & -.03 \\
Number of orthographic neighbors & $.49^{* * *}$ & -.02 \\
Length in characters & $.29^{* * *}$ & -.04 \\
Length in syllables & $.26^{* *}$ & $.15^{*}$ \\
Initial fricative & -.11 & $-.46^{* * *}$ \\
Imageability ratings & -.02 & $-.26^{* *}$ \\
Concreteness ratings &
\end{tabular}

$\sim p<.10 . \quad * p<.05 . \quad * * p<.01 . \quad * * * p<.001$.

the target word begins with a fricative. However, the various measures of length as well as number of orthographic neighbors correlated significantly with reading, but not with picture naming. Conversely, the two semantic measures (imageability and concreteness) and the objective measure of AoA correlated significantly with picture naming, but not with reading.

Table 3 summarizes correlations of the same 15 lexical predictors with each other. The predictors all bear a sensible theoretical relationship to word access in either one modality or both modalities. Of course, some of the correlations in Tables 2 and 3 are virtual tautologies, reflecting the relationship between closely related measures of the same construct (e.g., absolute vs. adjusted child frequency scores; two different ratings of AoA). We include them here to maximize comparability between the respective word-reading and picture-naming norming studies from which these shared items were drawn, since each study had made slightly different choices of predictors. Other correlations reflect more interesting relationships similar to those reported in previous studies, including the oft-cited correlations among frequency, familiarity, and AoA. Some of the correlations in Table 3 are not at all obvious. For example, even though concreteness and imageability correlate highly with each other, they differ in their pattern of correlations with other factors. However, the most important conclusion from Table 3 is the substantial degree of collinearity among these various predictors, requiring a multivariate approach in which the contribution of each predictor can be compared when variance from overlapping variables is controlled. Such results (and our multivariate strategy for dealing with them) are similar to what has been described in studies on English (e.g., Gilhooly \& Logie, 1981, 1982; Paivio, Clark, Digdon, \& Bons, 1989; Rubin, 1980; Whaley, 1978). 


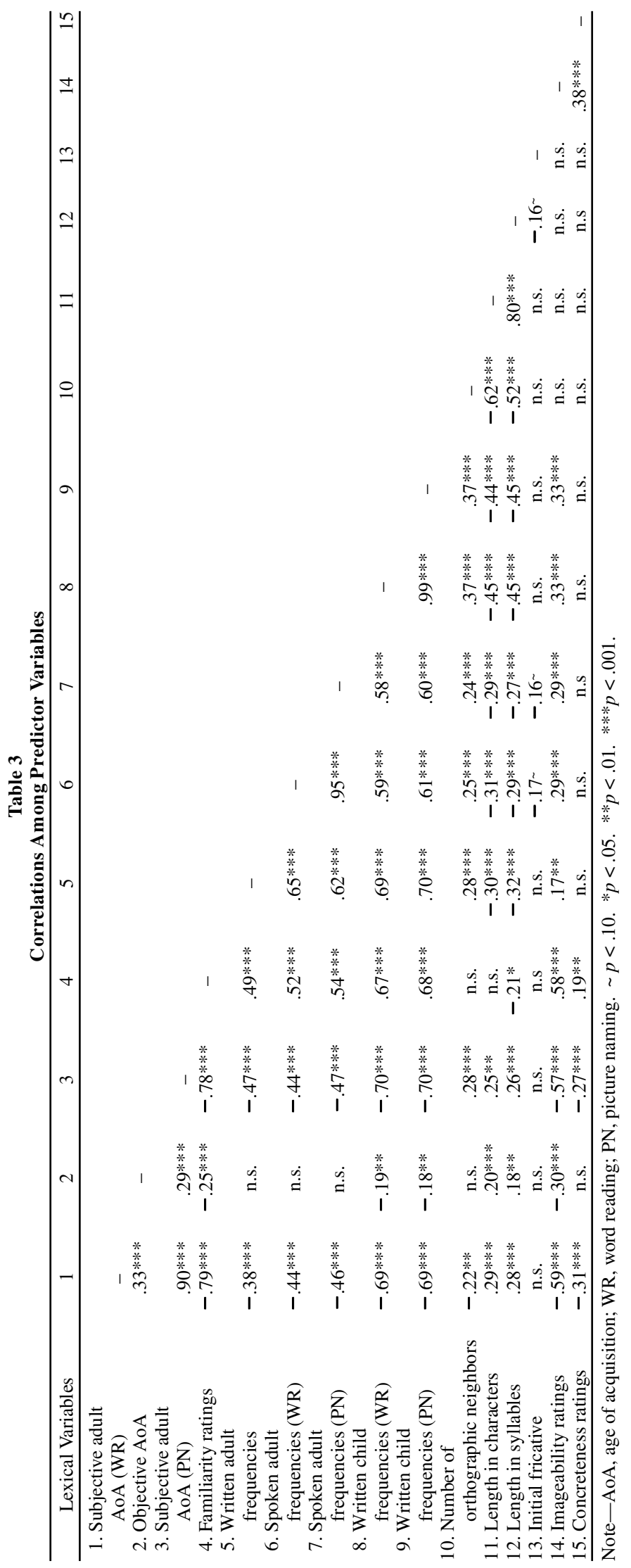




\section{Factor Analysis}

To deal with the collinearity among predictors reported above, a factor analysis (principal components analysis) was conducted, with the specific aim of reducing the number of variables in Tables 2 and 3 to a more manageable, coherent, and distinct subset. Four factors with eigenvalues greater than 1.0 emerged from this analysis. Factor loadings are summarized in Table 4.

The first factor accounted for $42.7 \%$ of the variance and loaded heavily on all the frequency measures, plus familiarity ratings, and two independent ratings of AoA (both based on subjective ratings by adults). Hence, this factor seems to unite the variance obtained with objective frequency norms and with subjective ratings of both familiarity and AoA, a finding in line with many others in the literature on lexical access (see the introduction).

The second factor accounted for $14.1 \%$ of the variance. It loaded heavily on all three AoA measures (including the objective measure taken from the MacArthur norms), plus familiarity ratings, and the two semantic variables (ratings of imageability and concreteness). The contrast between Factor 1 and Factor 2 is convenient, because it permits us to dissociate two aspects of both AoA and familiarity that have been confounded in most studies: frequency-related variance, and variance related to semantic factors and to the actual age at which the word was acquired. The finding that AoA loads with semantic variables is not surprising. It has been reported previously by other investigators (e.g., Paivio et al., 1989; Rubin, 1980; Whaley, 1978), and it follows from the raw correlations in Table 3 . This result also makes sense on theoretical grounds, since it is known that the first words acquired by young infants tend to be concrete, familiar, and highly imageable nouns (e.g., Bates, Bretherton, \& Snyder, 1988). The more interesting finding here is that this semantic aspect of the variance in AoA is at least partially dissociable from frequency per se (see also D'Amico et al., 2001; Paivio et al., 1989; Rubin, 1980). Furthermore, familiarity ratings load equally (and separately) on the respective frequency and semantic factors, indicating that the subjective ratings of word familiarity are affected by both the frequency of the word and the accessibility of the concept associated with that word. This may explain, at least in part, why familiarity effects tend to be very large for both lexical decision (Gernsbacher, 1984) and word reading (Treiman et al., 1995).

The third factor accounted for $9.8 \%$ of the variance and loaded primarily on length, including positive loadings for both length in characters and length in syllables and a large negative loading for orthographic neighborhood density.

Finally, the fourth factor accounted for $7.3 \%$ of the variance and was defined almost exclusively by the presence of an initial fricative, with very small and heterogeneous loadings from other factors.

\section{Regression Analyses With Factors as Variables}

With these four latent variables in hand, all with a relatively straightforward interpretation, we conducted stepwise regression analyses of naming latencies for each modality, assessing the contribution of each factor when it was entered into the equation on the last step. Results of these analyses are presented in Tables 5 and 6.

For word reading, the four factors together accounted for $28.6 \%$ of the RT variance (multiple $r=.53, p<.0001$ ). Three of the four factors made significant contributions when they were entered on the last step. The frequencydominant factor added $7.5 \%(p<.0005)$, with a partial correlation of -.31 , indicating that frequency, AoA, and familiarity jointly facilitate word-naming times. The length/neighborhood density factor added a large and significant $17.5 \%(p<.0001)$, with a partial correlation of +.44 , indicating that length slows down word-naming times when other factors are controlled. The semantics/ AoA/familiarity factor had no effect at all on reading times when the other factors were controlled, but the fourth factor (presence of an initial fricative) increased the variance accounted for by a small but significant $3.1 \%$ $(p<.023)$, with a partial correlation of +.20 , indicating that RTs for reading aloud are slower for words with an initial fricative when other factors are controlled (see also Treiman et al., 1995).

For picture naming, the four factors together accounted for $27.1 \%$ of the variance (multiple $r=.52, p<.0001$ ). Only two of the four factors made a unique and significant contribution when the other factors were controlled. The first factor added $9.7 \%(p<.0001)$, with a partial correlation of -.34 , indicating that frequency and those aspects of familiarity and AoA that overlap with frequency converge to facilitate picture-naming latencies. The second factor added a large and significant $15.9 \%$ on the last step $(p<.0001)$, with a partial correlation of -.42 , indicating that early acquisition, familiarity, and semantics (imageability and concreteness) jointly facilitate the time required to identify and name a picture, over and above the effects of frequency. The third factor (length/neighborhood

Table 4

Results of Factor Analysis Across Predictor Variables

\begin{tabular}{lrrrr}
\hline & \multicolumn{4}{c}{ Factor } \\
\cline { 2 - 5 } & 1 & \multicolumn{1}{c}{2} & 3 & \multicolumn{1}{c}{4} \\
\hline Subjective AoA (WR) & -.50 & -.75 & .15 & -.15 \\
Objective AoA & .08 & -.56 & .26 & .06 \\
Subjective AoA (PN) & -.55 & -.70 & .14 & -.13 \\
Familiarity ratings & .64 & .60 & .00 & .16 \\
Written adult frequencies & .84 & -.03 & -.17 & .01 \\
Spoken adult frequencies & & & & \\
$\quad$ WR & .85 & .07 & -.14 & -.29 \\
$\quad$ PN & .84 & .09 & -.12 & -.28 \\
Written child frequencies & & & & \\
$\quad$ WR & .78 & .31 & -.34 & .21 \\
$\quad$ PN & .80 & .30 & -.32 & .20 \\
Orthographic neighbors & .17 & .07 & -.76 & -.13 \\
Length in characters & -.19 & -.04 & .91 & .00 \\
Length in syllables & -.22 & -.03 & .85 & -.19 \\
Initial fricative & -.07 & -.12 & -.02 & .87 \\
Imageability ratings & .22 & .79 & .11 & -.12 \\
Concreteness ratings & -.01 & .54 & .03 & -.10 \\
\hline
\end{tabular}

Note-WR, word reading; PN, picture naming. Factors 1, 2, 3, and 4, respectively, accounted for $42.7 \%, 14.1 \%, 9.8 \%$, and $7.3 \%$ of variance. 
Table 5

Regression of Factor Scores on RT for Word Reading

\begin{tabular}{lccc}
\hline & \multicolumn{3}{c}{$\begin{array}{c}\text { Zero-Order } \\
\text { Partial } \\
\text { Correlation }\end{array}$} \\
& \% Variance & $p<$ \\
\hline Total (joint variance) & $28.6^{* * *}$ & .53 & .0001 \\
Factor 1: Frequency, AoA, & $7.5^{* * *}$ & -.31 & .0005 \\
$\quad$ and familiarity & & -.11 & n.s. \\
Factor 2: Semantics, AoA, & n.s. & .44 & .0001 \\
$\quad$ and familiarity & & .20 & .023 \\
Factor 3: Length and density & $17.1^{* * *}$ & & \\
Factor 4: Initial frication & $3.1^{*}$ & &
\end{tabular}

density) and fourth factor (initial fricative) had no effect on picture-naming times when the other factors were controlled.

Given the low correlation between word-reading and picture-naming latencies, together with the finding that each modality is affected by different predictors, we might well ask where all this nonoverlapping variance is coming from. The predictor variables listed in Table 2 were chosen for this study because they are all potentially relevant (directly or indirectly) to both word reading and picture naming. We did have other variables available in our respective reading and picture-naming databases, relevant to only one modality. For word reading, the most relevant of these was bigram frequency (see Andrews, 1997; Gernsbacher, 1984; Treiman et al., 1995). For picture naming, we had a much longer list of potential predictors at our disposal, but the most relevant (because of their unique value for the picture-naming task) were the following: $o b$ jective visual complexity, a measure of picture complexity based entirely on the size of each scanned, digitized, and compressed black-and-white image (Székely \& Bates, 2000); subjective ratings of goodness-of-depiction, a 1-7 scale administered to English-speaking college students, who were asked to rate how well the picture illustrates the target word produced by the largest number of Englishspeaking participants in the original naming study (Bates et al., 2000; equivalentratings are not yet available in Italian); and number of different (competing) target names provided by Italian-speaking participants in the original naming study (Bates et al., 2000; D'Amico et al., 2001).

To determine whether these variables might help to explain the "missing variance," we repeated the regression analyses just described for word and picture naming, but we then entered each of the remaining modality-specific predictor(s) on the final step.

For word reading, the only potentially relevant additional predictor was bigram frequency, which added a nonsignificant $0.7 \%$ to the total variance accounted for after the four factor scores were entered into the occasion (see also Barca et al., 2000).

For picture naming, results were quite different. Taken together, the four factor scores, objective visual complexity, subjective goodness-of-depiction ratings, and number of competing target names accounted for $61 \%$ of the variance in picture-naming latencies $(p<.0001)$. This repre- sents a substantial increase of $33.9 \%$ over the variance accounted for by the four factor scores alone $(27.1 \%)$. The unique contribution from objective visual complexity did not reach significance $(0.5 \%$, n.s. $)$, but very large and significant unique contributions were added by goodness-ofdepiction ratings $(10.9 \%, p<.0001)$ and by number of competing names $(14.2 \%, p<.0001)$.

In short, picture naming and word reading are weakly correlated because each is driven by a different set of predictor variables. The most important variables for picture naming include goodness-of-depiction, number of competing names for that picture, and the semantic factor that emerged in our principal components analysis. We may infer from these results that much of the variance in picture naming (which reading does not share) comes from the stages of stimulus encoding, recognition of the depicted object, and lexical selection. This interpretation is in line with our own previous findings for word reading in Italian, and it underscores the importance and utility of crossmodality comparisons.

\section{CONCLUSION}

In view of the low correlation that we observed between word-reading and picture-naming latencies, it is noteworthy that word access in these two modalities seems to be governed by different factors. Although both modalities are facilitated by word frequency (and those aspects of familiarity and AoA that overlap with frequency), the remaining contributions are distinct and complementary. Word reading in Italian (at least for these words) is strongly affected by length, neighborhood density, and initial frication, but it seems to be unaffected by semantic factors (imageability and concreteness) and/or those aspects of AoA and familiarity that remain when frequency is controlled. In contrast, picture naming in Italian (again, for these words) is strongly affected by semantic factors and frequency-independent aspects of familiarity and AoA, but it is unaffected by length, neighborhood density, and an initial fricative.

To interpret these results, we need to take into account differences between tasks and differences between languages. As predicted, the strong impact of semantics on picture naming and the negligible effect of this factor on word reading may reflect inherent differences between the

Table 6

Regression of Factor Scores on RT for Picture Naming

\begin{tabular}{|c|c|c|c|}
\hline & $\%$ Variance & $\begin{array}{c}\text { Zero-Order } \\
\text { Partial } \\
\text { Correlation } \\
\end{array}$ & $p<$ \\
\hline Total (joint variance) & $27.1 * * *$ & .52 & .0001 \\
\hline $\begin{array}{l}\text { Factor 1: Frequency, AoA, } \\
\text { and familiarity }\end{array}$ & $9.7 * * *$ & -.34 & .0001 \\
\hline $\begin{array}{l}\text { Factor 2: Semantics, AoA, } \\
\text { and familiarity }\end{array}$ & $15.9 * * *$ & -.42 & .0001 \\
\hline Factor 3: Length and density & n.s. & -.07 & n.s. \\
\hline Factor 4: Initial frication & n.s. & .13 & n.s. \\
\hline
\end{tabular}

$* * * p<.001$. 
two processes (Lambon Ralph, Cipolotti, \& Patterson, 1999). In picture naming, semantics is a crucial source of lexical activation (see, e.g., Humphreys et al., 1995; Johnson et al., 1996; Levelt et al., 1999). By contrast, word reading is fed by two main sources: one semantic and one orthographic-phonological. In reading, the latter source of activation is inherently strong and may be even stronger in languages with transparent orthographies, such as Italian. Indeed, it has been observed that the effects of AoA and frequency in more transparent languages are smaller than the effects usually reported in English (see, e.g., Brysbaert et al., 2000, for Dutch). It is worth noting here that the probability of lexical versus nonlexical single-word reading in Italian, as well as in other languages, is highly constrained by list composition (see Tabossi \& Laghi, 1992; Zevin \& Balota, 2000). Hence, it becomes relevant that, in our reading study, the list contained words with nondefault stress patterns, the main source of graphemephoneme unpredictability in Italian. Hence, this list composition did favor lexical look-up (see Method section), which should have allowed lexical-semantic effects, if any, to occur.

Nevertheless, the present data from Italian, a language with transparent orthography, indicate that semantic effects can disappear altogether when related variables are controlled (for additional evidence suggesting no semantic effects on reading larger samples of Italian words and null effects of AoA on Italian word reading after controlling for other factors, see Barca et al., 2000, and Burani, Barca, \& Arduino, 2001, respectively). And yet word reading does show effects of frequency when other factors are accounted for in a regression design. These unique contributions from frequency suggest that word reading in Italian does involve lexical access. In this regard, Burani et al. (2001) provided additional evidence for a role of frequency variables when related sublexical measures, such as bigram frequency (see Gernsbacher, 1984), are accounted for. However, the activation of lexical information in single-word reading does not necessarily imply that semantic information is activated as well. The presence of frequency effects in the absence of semantic effects contributes to the view that lexical reading does occur in Italian, with purely lexical reading potentially dissociable from lexical-semantic reading. What is not clear at this point is whether this nonsemantic lexical contribution is based on an amodal representation or whether it originates from a direct map between orthographic input lexical representations and phonological output representations, with no need for a semantic component to be activated (for similar findings and interpretations, see, e.g., Burani et al., 2000, Burani et al., 1999, Coltheart et al., 1993, and Peressotti \& Job, 1999, 2000; see also Buchanan \& Besner, 1993, for evidence that readers of the shallow Japanese Kana scripts use a nonsemantic, whole-word pathway to name words).

The pattern differs for picture naming, which is significantly affected by semantics when other variables are controlled. It is especially interesting in this regard that we were able to break both AoA and familiarity down into two kinds of variance: one loading on frequency and the other loading on semantics. This result (confirmed on a larger set of items by Barca et al., 2000) is in accordance with previous comprehensive factor analyses of attributes predictive of naming latencies for English, which showed AoA variance to be distributed across factors representing word meaning, word frequency, and word spelling-sound (Paivio et al., 1989; Rubin, 1980). What is new here, and what also needs to be assessed for English, is that the two kinds of variance seem to affect the two tasks differently. The first aspect (frequency dependent, independent of semantics) affects both word reading and picture naming. The second aspect (frequency independent, but correlated with semantics) affects picture naming but has no effect on reading. We may have been successful in isolating two different kinds of AoA variance also because we included an objective AoA measure in the data set, on the basis of parent report of first words in infancy. As has also been reported for other objective measures of AoA (Morrison et al., 1997; Morrison \& Ellis, 2000), this objective AoA measure is less correlated with frequency and has been shown to affect children's picture naming, while not eliminating frequency effects in regression analyses (D'Amico et al., 2001).

We also found effects of word form (length and frication) on word reading, but not on picture naming (for the absence of length effects on picture naming in English, see also Ellis \& Morrison, 1998, and their reanalyses of data from Barry et al., 1997, and Snodgrass \& Yuditsky, 1996). Why was this the case? At this point, we can only speculate, but it is worth pointing out that word-reading times were substantially faster than were picture-naming times for the same words in this study (and in other studies; e.g., Potter et al., 1986). It is possible that factors such as frication and word length have their greatest effects at the early stages of motor speech planning, independent of the factors involved in comprehension of the picture and the associated concept that must be named. Because word-reading times are so fast, they may be affected by speech-planning factors that are no longer detectable in the RT range tapped by picture naming. It would be interesting to determine whether speeded picture-naming studies, in which participants are placed under even greater pressures to name pictures on the basis of minimal visual input, might yield effects of word structure (including phonological properties and length) that are not evident in the picturenaming times represented here but are detected in reading times. Up to now, speeded picture naming has been used mainly to induce higher error rates, thus supporting the conclusion that this task limited processing time primarily at the level of word selection (Vitkovich \& Humphreys, 1991; Vitkovitch, Humphreys, \& Lloyd-Jones, 1993). If RTs were taken as the dependent variable in speeded picture naming, the effects of variables having to do with the activation and production of phonologicalword forms might appear. While leaving intact or even enhancing lexical- 
semantic effects, speeded picture naming might shed further light on more peripheral components involved in the naming process.

A different processing component-namely, an orthographic input component (present in word reading but not in picture naming) - might also be involved in the wordlength effect that we found for reading but not for picture naming. Indications that length affects the visual recognition of words come from studies conducted on both English and less opaque languages, such as Dutch and Italian, in which analogously strong effects of word length were found in both word naming and visual lexical decision, a task in which no verbal output is involved (see, e.g., Butler \& Hains, 1979, Gilhooly \& Logie, 1981, 1982, and Morrison \& Ellis, 2000, for English; Hudson \& Bergman, 1984, for Dutch; Burani et al., 2001, and Burani et al., 2000, for Italian).

In short, these results point to a dissociation between tasks, highlighting the different processes involved in word reading and picture naming: word-form effects (orthographicphonological)for word reading, and semantic-conceptual effects (which also load on AoA and familiarity) for picture naming. At the same time, the finding that both tasks are affected by lexical frequency suggests that picture naming and word reading do share a lexical component. This result is partially compatible with the three-stage model of picture naming proposed in a recent review by Johnson et al. (1996), who emphasized the different factors that influence picture decoding, lexical selection, and motor output. However, as noted above, we did not find the word-length effect on motor output predicted by the Johnson et al. model. Our results are also compatible with models that postulate an amodal lexical level shared by picture naming, word reading, and other tasks. Although our findings do not permit us to decide between these competing hypotheses, they suggest that such models (which are usually based on data from one modality) may be extended fruitfully to cross-modality comparisons.

Finally, the dissociations reported here for Italian word reading (including the dissociation from picture naming, and the internal dissociation between semantic and lexical effects) should be complemented by studies across languages with different degrees of orthographic depth, including English. It would also be useful to replicate these results with larger samples of items and in within-subjects designs that permit a comparison of modality effects in the same participants. We have recently initiated such crosslinguistic comparisons of reading and picture naming in three languages, with three different writing systems: English (an opaque alphabetic system), Italian (a transparent alphabetic system), and Chinese (a logographic system).

\section{REFERENCES}

ANDREWS, S. (1997). The effect of orthographic similarity on lexical retrieval: Resolving neighborhood conflicts. Psychonomic Bulletin \& Review, 4, 439-461.

Arduino, L. S., \& Burani, C. (2000). Neighborhood effects on pseudoword visual processing in a language with shallow orthography. Manuscript submitted for publication.
Baldi, P. L., \& Traficante, D. (2000). Modelli di lettura e metodi di ricerca sulla somiglianza ortografica [Reading models and research methods for orthographic similarity]. Rome: Carocci.

Balota, D. A., Ferraro, F. R, \& Connor, L. T. (1991). On the early influence of meaning in word recognition: A review of the literature. In I. P. Schwanenflugel (Ed.), The psychology of word meaning (pp. 187-222). Hillsdale, NJ: Erlbaum.

Barca, L., Burani, C., \& Arduino, L. S. (2000). Norms for age-ofacquisition, frequency, familiarity, imageability, concreteness, and other lexical and sublexical variables for 626 Italian nouns, and effects on word reading. Manuscript submitted for publication.

Barry, C., Morrison, C. M., \& Ellis, A. W. (1997). Naming the Snodgrass and Vanderwart pictures: Effects of age of acquisition, frequency, and name ag reement. Quarterly Journal of Experimental Psychology, 60, 560-585.

Bates, E., Andonova, E., D’ Amico, S., Jacobsen, T., Kohnert, K., Lu, C.-C., Székely, A., Wicha, N., Federmeier, K., Herron, D., Iyer, G., Pechmann, T., Devescovi, A., Orozco-Figueroa, A., Gutierrez, G., Hung, D., Hsu, J., Tzeng, O., Gerdjikova, G., Mehotcheva, T., \& PléH, C. (2000). Introducing the CRL international picture-naming project (CRL-IPNP) (Center for Research in Language Newsletter, Vol. 12, No. 1). La Jolla: University of California, San Diego.

Bates, E., Bretherton, I., \& Snyder, L. (1988). From first words to grammar: Individual differences and dissociable mechanisms. New York: Cambridge University Press.

Bentrovato, S., Devescovi, A., D' Amico, S., \& Bates, E. (1999). The effect of grammatical gender and semantic context on lexical access in Italian. Journal of Psycholinguistic Research, 28, 677-693.

Brysbaert, M., Lange, M., \& VAN Wijnendaele, I. (2000).The effects of age-of-acquisition and frequency-of-occurrence in visual word recognition: Further evidence from the Dutch language. European Journal of Cognitive Psychology, 12, 65-85.

BuchanAN, L., \& BeSner, D. (1993). Reading aloud: Evidence for the use of a whole word nonsemantic pathway. Canadian Journal of Experimental Psychology, 47, 133-152.

Burani, C., Barca, L., \& Arduino, L. S. (2001). Lexical effects in accessing and naming Italian nouns. Manuscript in preparation.

Burani, C., Barca, L., \& Arduino, L. S. (in press). Una base di dati sui valori di età di acquisizione, frequenza, familiarità, immaginabilità, concretezza, e altre variabili lessicali e sublessicali per 626 nomi dell'italiano [A database of values for age of acquisition, frequency, familiarity, imageability, concreteness and other lexical and sublexical variables for 626 Italian nouns]. Giornale Italiano di Psicologia.

Burani, C., Dovetto, F. M., Spuntarelli, A., \& Thornton, A. M. (1999). Morpholexical access and naming: The semantic interpretability of new root-suffix combinations. Brain \& Language, 68, 333-339.

Burani, C., \& Laudanna, A. (in press). Morpheme-based lexical reading: Evidence from pseudoword naming. In E. Assink \& D. Sandra (Eds.), Reading complex words. Dordrecht: Kluwer.

Burani, C., Marcolini, S., \& Stella, G. (2000, October). How early is the development of morpholexical reading in a language with shallow orthography? Paper presented at the Second International Conference on the Mental Lexicon, Montreal.

BUTLER, B., \& HAINS, S. (1979). Individual differences in word recognition latency. Memory \& Cognition, 7, 68-76.

Carroll, J. B., \& White, M. N. (1973a). Age of acquisition norms for 220 pictureable nouns. Journal of Verbal Learning \& Verbal Behavior, 12, 563-576.

Carroll, J. B., \& White, M. N. (1973b). Word frequency and age of acquisition as determiners of picture-naming latency. Quarterly Journal of Experimental Psychology, 25, 85-95.

Caselli, M. C., \& Casadio, P. (1995). Il primo vocabolario del bambino: Guida all'uso del questionario MacArthur per la valutazione della comunicazione e del linguaggio nei primi anni di vita [The child's first words: Guide for the use of the MacArthur questionnaire for assessing communication and language in the first years of life]. Milan: FrancoAngeli.

Cattell, J. (1886). The time to see and name objects. Mind, 11, 63-65.

Cohen, J., MacWhinney, B., Flatt, M., \& Provost, J. (1993). PsyScope: An interactive graphic system for designing and controlling 
experiments in the psychology laboratory using Macintosh computers. Behavior Research Methods, Instruments, \& Computers, 25, 257-271.

Colombo, L. (1992). Lexical stress effect and its interaction with frequency in word pronunciation. Journal of Experimental Psychology: Human Perception \& Performance, 18, 987-1003.

Colombo, L., \& Taвossi, P. (1992). Strategies and stress assignment: Evidence from a shallow orthography. In R. Frost \& L. Katz (Eds.), Orthography, phonology, morphology, and meaning (pp. 319-340). Amsterdam: North-Holland.

Coltheart, M., Curtis, B., Atrins, P., \& Haller, M. (1993). Models of reading aloud: Dual-route and parallel-distributed-processing approaches. Psychological Review, 100, 589-608.

Coltheart, M., Davelaar, E., Jonasson, J. T., \& Besner, D. (1977). Access to the internal lexicon. In S. Dornic (Ed.), Attention and performance VI (pp. 535-555). Hillsdale, NJ: Erlbaum.

Connine, C. M., Mullennix, J., Shernoff, E., \& Yelen, J. (1990). Word familiarity and frequency in visual and auditory word recognition. Journal of Experimental Psychology: Learning, Memory, \& Cognition, 6, 1084-1096.

Cortese, M. J., Simpson, G. B., \& Woolsey, S. (1997). Effects of association and imageability on phonological mapping. Psychonomic Bulletin \& Review, 4, 226-231.

D’Amico, S., Devescovi, A., \& Bates, E. (2001). Picture naming and lexical access in Italian children and adults. Journal of Cognition \& Development, 2, 71-105.

De Mauro, T., Mancini, F., Vedovelli, M., \& Voghera, M. (1993). Lessico di frequenza dell'italiano parlato [Frequency lexicon of spoken Italian]. Milan: ETASLIBRI.

Ellis, A. W., \& Morrison, C. M. (1998). Real age-of-acquisition effects in lexical retrieval. Journal of Experimental Psychology: Learning, Memory, \& Cognition, 24, 515-523.

Federmeier, K. (1999). Sense and structure: Electrophysiological investigations of semantic memory organization and use. Unpublished doctoral dissertation, University of California, San Diego.

Federmeier, K., \& BATES, E. (1997). Contexts that pack a punch: Lexical class priming of picture naming (Center for Research in Language Newsletter, Vol. 11, No. 2). La Jolla: University of California, San Diego.

Federmeier, K., \& Kutas, M. (1999a). Right words and left words: Electrophysiological evidence for hemispheric differences in meaning processing. Cognitive Brain Research, 8, 373-392.

Federmeier, K., \& Kutas, M. (1999b). A rose by any other name: Long-term memory structure and sentence processing. Journal of Memory \& Language, 41, 469-495.

Federmeier, K. D., \& KutAs, M. (2001). Meaning and modality: Influences of context, semantic memory organization, and perceptual predictability in picture processing. Journal of Experimental Psychology: Learning, Memory \& Cognition, 27, 202-224.

Fenson, L., Dale, P. A., Reznick, J. S., Bates, E., Thal, D., \& Pethick, S. J. (1994). Variability in early communicative development. Monographs of the Society for Research in Child Development, 59 (5, Serial No. 242).

Frost, R. (1994). Prelexical and postlexical strategies in reading: Evidence from a deep and a shallow orthography. Journal of Experimental Psychology: Learning, Memory, \& Cognition, 20, 116-129.

Frost, R., Katz, L., \& Bentin, S. (1987). Strategies for visual word recognition and orthographical depth: A multilingual comparison. Journal of Experimental Psychology: Human Perception \& Performance, 13, 104-115.

Gerhand, S., \& BARry, C. (1998) Word frequency effects in oral reading are not merely age-of-acquisition effects in disguise. Journal of Experimental Psychology: Learning, Memory, \& Cognition, 24, $267-$ 283.

Gernsbacher, M. A. (1984). Resolving 20 years of inconsistent interactions between lexical familiarity and orthography, concreteness, and polysemy. Journal of Experimental Psychology: General, 113, 256-281.

Gilhooly, K. J., \& LogIE, R. H. (1981). Word age-of-acquisition, reading latencies and auditory recognition. Current Psychological Research, 1, 251-262.

Gilhooly, K. J., \& Logie, R. H. (1982). Word age-of-acquisition and lexical decision making. Acta Psychologica, 50, 21-34.
Hudson, P. T. W., \& Bergman, M. W. (1984). Lexical knowledge in word recognition: Word length and word frequency in naming and lexical decision tasks. Journal of Memory \& Language, 24, 46-58.

Humphreys, G. W., Lamote, C., \& Lloyd-Jones, T. J. (1995). An interactive activation approach to object processing: Effects of structural similarity, name frequency, and task in normality and pathology. Memory, 3, 535-586.

Istituto di Linguistica Computazionale del CNR di Pisa (1989). Corpus di Italiano scritto contemporaneo [Corpus of contemporary written Italian]. Unpublished manuscript.

JACOBSEN, T. (1999). Effects of grammatical gender on picture and word naming: Evidence from German. Journal of Psycholinguistic Research, 28, 499-514.

Job, R, Peressotti, F., \& Cusinato A. (1998). Lexical effects in naming pseudowords in shallow orthographies: Further empirical data. Journal of Experimental Psychology: Human Perception \& Performance, 24, 622-630.

Johnson, C. J., Paivio, A., \& Clark, J. M. (1996). Cognitive components of picture naming. Psychological Bulletin, 120, 113-139.

Lambon Ralph, M. A., Cipolotti, L., \& Patterson, K. (1999). Oral naming and oral reading: Do they speak the same language? Cognitive Neuropsychology, 16, 157-169.

Levelt, W. J. M., Roelofs, A., \& Meyer, A. S. (1999). A theory of lexical access in speech production. Behavioral \& Brain Sciences, 22, 1-75.

Lu, C.-C., Bates, E, Hung, D., Tzeng, O., Hsu, J., Tsai, C.-H., \& Roe, K. (2000). Syntactic priming of nouns and verbs in Chinese (Tech. Rep. No. CRL-0001). La Jolla: University of California, San Diego, Center for Research in Language.

Marconi, L., Ott, M., Pesenti, E., Ratti, D., \& Tavella, M. (1993). Lessico elementare: Dati statistici sull'italiano scritto e letto dai bambinidelle elementari [Elementary lexicon: Statistical data for Italian written and spoken by elementary school children]. Bologna: Zanichelli.

Moore, V., Valentine,T., \& Turner, J. (1999). Age-of-acquisition and cumulative frequency have independent effects. Cognition, 72, 305-309.

Morrison, C. M., Chappell, T. D., \& Ellis, A. W. (1997). Age of acquisition norms for a large set of object names and their relation to adult estimates and other variables. Quarterly Journal of Experimental Psychology, 50A, 528-559.

Morrison, C. M., \& Ellis, A. W. (1995). The role of word frequency and age of acquisition in word naming and lexical decision. Journal of Experimental Psychology: Learning, Memory, \& Cognition, 21, 116133.

Morrison, C. M., \& Ellis, A. W. (2000). Real age of acquisition effects in word naming and lexical decision. British Journal of Psychology, 91, 167-180.

Morrison, C. M., Ellis, A. W., \& Quinlan, P. T. (1992). Age of acquisition, not word frequency, affects object naming, not object recognition. Memory \& Cognition, 20, 705-714.

Noble, C. E. (1953). The meaning-familiarity relationship. Psychological Review, 60, 89-98.

Paivio, A., Clark, J. M., Digdon, N., \& Bons, T. (1989). Referential processing: Reciprocity and correlates of naming and imaging. Memory \& Cognition, 17, 163-174.

Paivio, A., Yuille, J. C., \& Madigan, S. A. (1968). Concreteness, imagery, and meaningfulness values for 925 nouns. Journal of Experimental Psychology Monograph Supplement, 71, 1-9.

Paulesu, E, McCrory, E., Fazio, F., Menoncello,L., Brunswick, N., Cappa, S. F., Cotelli, M., Cossu, G., Corte, F., Lorusso, M., Pesenti, S., Gallagher, A., Perani, D., Price, C., Frith, C. D., \& Frith, U. (2000). A cultural effect on brain function. Nature Neuroscience, 3, 91-96.

Peressotti, F., \& Job, R. (1999). Functional constraints and multiple procedures in reading. In S. Bagnara (Ed.), Proceedings of ECCS'99European Conference on Cognitive Science (pp. 309-314). Siena: Multimedia \& Communication.

Peressotti, F., \& JoB, R. (2000). Reading aloud: Dissociating the semantic pathway from the non-semantic pathway of the lexical route. Manuscript submitted for publication.

Plaut, D. C., McClelland, J. L., Seidenberg, M. S., \& PatterSON, K. E. (1996). Understanding normal and impaired word reading: 
Computational principles in quasi-regular domain. Psychological Review, 103, 56-115.

Potter, M., \& FAulconer,B. (1975). Time to understand pictures and words. Nature, 254, 437-438.

Potter, M., Kroll, J., Yachzel, B., Carpenter, E., \& Sherman, J. (1986). Pictures in sentences: Understanding without words. Journal of Experimental Psychology: General, 115, 281-294.

Roe, K., Jahn-Samilo, J., Juarez, L., Mickel, N., Royer, I., \& Bates, E. (2000). Contextual effects on word production: A lifespan study. Memory \& Cognition, 28, 756-765.

Rubin, D. C. (1980). 51 properties of 125 words: A unit analysis of verbal behavior. Journal of Verbal Learning \& Verbal Behavior, 19, 736755 .

Snodgrass, J. G., \& Vanderwart, M. (1980). A standardized set of 260 pictures: Norms for name agreement, familiarity, and visual complexity. Journal of Experimental Psychology: Human Learning \& Memory, 6, 174-215.

SNOdgrass, J. G., \& Yuditsky, T. (1996). Naming times for the Snodgrass and Vanderwart pictures. Behavior Research Methods, Instruments, \& Computers, 28, 516-536.

Strain, E., Patterson, K., \& Seidenberg, M. S. (1995). Semantic effects in single-word naming. Journal of Experimental Psychology: Learning, Memory, \& Cognition, 21, 1140-1154.

SzÉKELY, A., \& BATES, E. (2000). Objective visual complexity as a variable in studies of picture naming (Center for Research in Language Newsletter, Vol. 12, No. 2). La Jolla: University of California, San Diego.
TABossi, P., \& LAGHI, L. (1992). Semantic priming in the pronunciation of words in two writing systems: Italian and English. Memory \& Cognition, 20, 303-313.

Treiman, R., Mullennix, J., Bijeljac-Babic, R., \& RichmondWeLty, E. D. (1995). The special role of rimes in the description, use, and acquisition of English orthography. Journal of Experimental Psychology: General, 124, 107-137.

Vitkovitch, M., \& Humphreys, G. W. (1991). Perseverant responding in speeded naming of pictures: It's in the links. Journal of Experimental Psychology: Learning, Memory, \& Cognition, 17, 664-680.

Vitkovitch, M., Humphreys, G. W., \& Lloyd-Jones, T. J. (1993). On naming a giraffe a zebra: Picture-naming errors across different objects. Journal of Experimental Psychology: Learning, Memory, \& Cognition, 19, 243-259.

WEEKES, B. S. (1997). Differential effects of number of letters on word and nonword naming latency. Quarterly Journal of Experimental Psychology, 50A, 439-456.

Whaley, C. P. (1978). Word-nonword classification time. Journal of Verbal Learning \& Verbal Behavior, 17, 143-154.

Wicha, N., Bates, E., Hernandez, A., Reyes, I., \& Gavaldón de BarRETO, L. (1997). When zebras become painted donkeys: Interplay between gender and semantic priming in a Spanish sentence context (Tech. Rep. No. 9701). La Jolla: University of California, San Diego, Center for Research in Language.

Zevin, J. D., \& BAlota, M. S. (2000). Priming and attentional control of lexical and sublexical pathways during naming. Journal of Experimental Psychology: Learning, Memory, \& Cognition, 26, 121-135.

\section{APPENDIX A \\ Instructions for Subjective Ratings for the Reading Study}

\section{Age of Acquisition Ratings}

In this study, we need your estimates of the age at which you think you first learned each of a series of words, that is, first learned the word and its meaning, either in spoken or written form.

In the following pages you will find a list of words.

\begin{tabular}{lcccccc}
\multicolumn{7}{c}{ learned at the ages of } \\
$0-2$ & $3-4$ & $5-6$ & $7-8$ & $9-10$ & $11-12$ & $13+$ \\
years & years & years & years & years & years & years \\
1 & 2 & 3 & 4 & 5 & 6 & 7
\end{tabular}

Your task is to indicate the age at which you think you learned each word.

Rate each word by crossing the number that best indicates the age at wich you think you learned that word.

If you think you learned a word at the age of 7 years, then you would cross the " 4 " on the scale beside that word; if you think you learned a word at the age of 1 year, then you would cross the " 1 " on the scale beside that word; and so on.

Feel free to use all the numbers on the scale, and do not be concerned about how often you use a number.

\section{Familiarity Ratings}

In the following pages you will find a list of words.

Each word has an accompanying scale. The scale ranges from 1 to 7 , as follows:

very little known

12

3

very well known
Your task is to rate how well you think each word is known by students like you.

Rate each word by crossing the number that best indicates your judgment.

Keep in mind that the " 1 " corresponds to very little-known words, and the "7" to the words that you think are very well known by students like you. Use the intermediate numbers for intermediate degrees of knowledge.

Feel free to use all the numbers on the scale.

Rate each word only once. Remember to rate every word.

\section{Imageability Ratings}

Words differ in their capacity to arouse mental images of things or events. Some words arouse a sensory experience, such as a mental picture or sound, more quickly and easily than others. In the following pages you will find a list of words.

Each word has an accompanying scale. The scale ranges from 1 to 7 , as follows:

$$
\begin{array}{ccccccc}
\text { hardly } & \multicolumn{3}{c}{\text { highly imageable }} \\
1 & 2 & 3 & 4 & 5 & 6 & 7
\end{array}
$$

Your task is to rate each word. The words that arouse a mental image very quickly and easily should be given a high rating; words that arouse images with the greatest difficulty or not at all should be given a low rating.

Feel free to use all the numbers on the scale, and do not be concerned about how often you use a number.

Rate each word by crossing the number that best indicates your judgment. 


\title{
APPENDIX A (Continued)
}

\section{Concreteness Ratings}

The words that refer to objects, living beings, actions and materials that can be experienced by the senses, can be considered as "concrete." Words that refer to concepts that cannot be experienced by the senses, can be considered as "abstract."

In the following pages you will find a series of words.

Each word has an accompanying scale. The scale ranges from 1 to 7, as follows:

highly abstract

12
2

3

highly concrete
Your task is to rate each word for its degree of concreteness or abstractness.

Rate each word, considering that the high ratings should be given to concrete words, and the low ratings to abstract words. When you rate a word as being neither fully concrete nor fully abstract, give it an intermediate value.

Feel free to use all the numbers on the scale, and do not be concerned about how often you use a number.

Rate each word by crossing the number that best indicates your judgment.

\section{APPENDIX B \\ Instructions for Subjective Ratings for the Picture-Naming Study}

\begin{abstract}
Age of Acquisition
You will see a list of words presented one at a time on the computer screen. We need your estimate of when in your life you think you first learned the meaning of each of the words that you see, i.e., first learned the word and its meaning either in spoken or written form. We are aware that it might be difficult to remember exactly. Therefore please give us your best estimate of when you think you learned the meaning of the word, even if you have to guess.
\end{abstract}

You are provided with a 9-point scale to give your best estimate of the age you acquired the word. The 9-point scale is:

\begin{tabular}{lll}
\multicolumn{1}{c}{ Age } & \multicolumn{1}{c}{ Grade } & Keyboard Code \\
\hline $\begin{array}{l}\text { 2 years } \\
\text { (and under) }\end{array}$ & Prenursery & 1 \\
3 years & Prenursery & 2 \\
4 years & Nursery & 3 \\
5 years & Kindergarten & 4 \\
6 years & First Grade & 5 \\
7-8 years & Second, Third & 6 \\
9-10 years & Fourth, Fifth & 7 \\
11-12 years & Sixth, Seventh & 8 \\
13+ years & Eighth and above & 9
\end{tabular}

Respond to each word by pressing any of the nine keys specified on the keyboard. Try and respond as quickly as you can. Also, since you won't be able to change your responses, be careful that the response you give is what you wanted to choose.

You may take a break whenever you wish. Press the space bar to pause the experiment and press the space bar again to resume the experiment. 
APPENDIX C

List of Italian Words and Their English Translations, as well as RT Word-Reading (RT-WR), RT Picture-Naming (RT-PN), $z$-Score Word-Reading ( $z$-WR), and $z$-Score Picture Naming ( $z$-PN) Results

\begin{tabular}{|c|c|c|c|c|c|c|c|c|c|c|c|}
\hline Italian & English & $\begin{array}{c}\text { RT-WR } \\
(\mathrm{msec})\end{array}$ & $\begin{array}{l}\text { RT-PN } \\
(\mathrm{msec})\end{array}$ & $z$-WR & $z-\mathrm{PN}$ & Italian & English & $\begin{array}{l}\text { RT-WR } \\
(\mathrm{msec})\end{array}$ & $\begin{array}{l}\text { RT-PN } \\
(\mathrm{msec})\end{array}$ & $z$-WR & $z-\mathrm{PN}$ \\
\hline 1. aquila & eagle & 501 & 1,257 & -0.92 & 0.95 & 65. luna & moon & 492 & 757 & -1.25 & -1.32 \\
\hline 2. aragosta & lobster & 513 & 1,545 & -0.49 & 2.26 & 66. lupo & wolf & 482 & 1,299 & -1.65 & 1.14 \\
\hline 3. balcone & balcony & 518 & 1,192 & -0.3 & 0.66 & 67. maiale & pig & 496 & 1,122 & -1.11 & 0.34 \\
\hline 4. banana & banana & 545 & 770 & 0.69 & -1.26 & 68. mano & hand & 516 & 742 & -0.37 & -1.39 \\
\hline 5. barba & beard & 515 & 1,050 & -0.4 & 0.01 & 69. matita & pencil & 523 & 885 & -0.13 & -0.74 \\
\hline 6. bastone & cane & 507 & 1,156 & -0.7 & 0.49 & 70. medaglia & medal & 513 & 1,164 & -0.49 & 0.53 \\
\hline 7. bicchiere & wineglass & 559 & 835 & 1.23 & -0.97 & 71. mela & apple & 494 & 904 & -1.20 & -0.65 \\
\hline 8. bocca & lips & 483 & 814 & -1.58 & -1.06 & 72. moneta & coin & 483 & 1,019 & -1.59 & -0.13 \\
\hline 9. bomba & bomb & 512 & 1,167 & -0.54 & 0.54 & 73. mucca & cow & 482 & 1,018 & -1.64 & -0.13 \\
\hline 10. burro & butter & 531 & 1,413 & 0.18 & 1.66 & 74. mulino & windmill & 490 & 1,109 & -1.32 & 0.28 \\
\hline 11. calamita & magnet & 562 & 1,179 & 1.34 & 0.6 & 75. naso & nose & 495 & 728 & -1.13 & -1.45 \\
\hline 12. camino & chimney & 530 & 1,208 & 0.13 & 0.73 & 76. nave & ship & 493 & 978 & -1.23 & -0.32 \\
\hline 13. cammello & camel & 537 & 962 & 0.4 & -0.39 & 77. nido & nest & 513 & 1,137 & -0.50 & 0.41 \\
\hline 14. candela & candle & 534 & 786 & 0.31 & -1.19 & 78. nodo & knot & 526 & 1,211 & -0.01 & 0.74 \\
\hline 15. cane & $\operatorname{dog}$ & 507 & 768 & -0.72 & -1.27 & 79. nuvola & cloud & 520 & 1,335 & -0.23 & 1.30 \\
\hline 16. canguro & kangaroo & 542 & 888 & 0.58 & -0.72 & 80. orso & bear & 474 & 906 & -1.93 & -0.64 \\
\hline 17. capra & goat & 517 & 1,203 & -0.33 & 0.71 & 81. pacco & package & 521 & 1,123 & -0.18 & 0.34 \\
\hline 18. carciofo & artichoke & 545 & 1,046 & 0.69 & -0.01 & 82. padella & pan & 517 & 1,042 & -0.32 & -0.03 \\
\hline 19. carota & carrot & 527 & 971 & 0.02 & -0.35 & 83. pala & shovel & 502 & 1,043 & -0.89 & -0.02 \\
\hline 20. casa & house & 505 & 835 & -0.77 & -0.97 & 84. palma & palmtree & 509 & 1,050 & -0.65 & 0.01 \\
\hline 21. castello & castle & 508 & 1,029 & -0.66 & -0.08 & 85. pane & bread & 494 & 1,123 & -1.18 & 0.34 \\
\hline 22. cavallo & horse & 500 & 839 & -0.97 & -0.95 & 86. parrucca & wig & 531 & 1,062 & 0.19 & 0.07 \\
\hline 23. cervo & deer & 534 & 1,231 & 0.29 & 0.83 & 87. patata & potato & 516 & 1,369 & -0.38 & 1.46 \\
\hline 24. chiesa & church & 536 & 1,026 & 0.36 & -0.1 & 88. pecora & sheep & 513 & 1,297 & -0.5 & 1.13 \\
\hline 25. chitarra & guitar & 564 & 798 & 1.39 & -1.13 & 89. pentola & pot & 541 & 1,097 & 0.54 & 0.22 \\
\hline 26. ciliegia & cherry & 585 & 1,210 & 2.18 & 0.74 & 90. pettine & comb & 529 & 709 & 0.11 & -1.54 \\
\hline 27. coltello & knife & 506 & 941 & -0.74 & -0.48 & 91. pinguino & penguin & 591 & 1,157 & 2.38 & 0.5 \\
\hline 28. coniglio & rabbit & 534 & 852 & 0.31 & -0.89 & 92. pioggia & rain & 523 & 926 & -0.13 & -0.55 \\
\hline 29. cravatta & tie & 556 & 866 & 1.1 & -0.82 & 93. pipa & pipe & 504 & 773 & -0.81 & -1.25 \\
\hline 30. cubo & cube & 514 & 1,436 & -0.44 & 1.76 & 94. piramide & pyramid & 538 & 947 & 0.44 & -0.46 \\
\hline 31. cucchiaio & spoon & 577 & 849 & 1.89 & -0.9 & 95. piscina & pool & 538 & 990 & 0.44 & -0.26 \\
\hline 32. cuore & heart & 516 & 694 & -0.38 & -1.61 & 96. pistola & gun & 548 & 803 & 0.8 & -1.11 \\
\hline 33. cuscino & pillow & 574 & 1,043 & 1.76 & -0.02 & 97. piuma & feather & 549 & 1,006 & 0.83 & -0.19 \\
\hline 34. divano & sofa & 505 & 870 & -0.78 & -0.81 & 98. pollice & thumb & 513 & 1,231 & -0.49 & 0.83 \\
\hline 35. doccia & shower & 520 & 1,039 & -0.23 & -0.04 & 99. ponte & bridge & 506 & 1,069 & -0.74 & 0.1 \\
\hline 36. donna & woman & 502 & 1,142 & -0.89 & 0.43 & 100. racchetta & tennis racket & 588 & 915 & 2.28 & -0.6 \\
\hline 37. drago & dragon & 520 & 1,047 & -0.23 & 0 & 101. ragno & spider & 506 & 978 & -0.76 & -0.32 \\
\hline 38. elefante & elephant & 504 & 879 & -0.8 & -0.77 & 102. rana & frog & 533 & 899 & 0.27 & -0.67 \\
\hline 39. fantasma & ghost & 508 & 937 & -0.67 & -0.5 & 103. rubinetto & faucet & 570 & 1,166 & 1.63 & 0.54 \\
\hline 40. farfalla & butterfly & 516 & 736 & -0.37 & -1.41 & 104. scimmia & monkey & 553 & 1,041 & 1.01 & -0.03 \\
\hline 41. faro & lighthouse & 527 & 1,107 & 0.03 & 0.27 & 105. secchio & trashcan & 540 & 1,364 & 0.52 & 1.44 \\
\hline 42. finestra & window & 551 & 942 & 0.93 & -0.48 & 106. sedia & chair & 555 & 771 & 1.07 & -1.26 \\
\hline 43. foca & walrus & 526 & 1,218 & -0.02 & 0.77 & 107. serpente & snake & 548 & 849 & 0.8 & -0.9 \\
\hline 44. frate & monk & 516 & 1,344 & -0.37 & 1.35 & 108. spada & sword & 591 & 1,056 & 2.41 & 0.04 \\
\hline 45. freccia & arrow & 549 & 859 & 0.84 & -0.86 & 109. statua & statue & 583 & 1,059 & 2.08 & 0.05 \\
\hline 46. fucile & rifle & 536 & 895 & 0.37 & -0.69 & 110. tamburo & drum & 513 & 827 & -0.48 & -1 \\
\hline 47. fulmine & lightning & 535 & 1,032 & 0.32 & -0.07 & 111. tappeto & rug & 531 & 895 & 0.2 & -0.69 \\
\hline 48. fuoco & fire & 536 & 953 & 0.36 & -0.43 & 112. tartaruga & turtle & 542 & 836 & 0.6 & -0.96 \\
\hline 49. gabbia & cage & 507 & 974 & -0.71 & -0.33 & 113. tetto & roof & 561 & 1,035 & 1.28 & -0.06 \\
\hline 50. gatto & cat & 515 & 834 & -0.43 & -0.97 & 114. topo & mouse & 505 & 1,036 & -0.76 & -0.05 \\
\hline 51. genio & genie & 537 & 1,272 & 0.38 & 1.02 & 115. torta & cake & 516 & 925 & -0.39 & -0.56 \\
\hline 52. giacca & jacket & 524 & 1,122 & -0.08 & 0.34 & 116. trappola & mousetrap & 524 & 1,580 & -0.08 & 2.42 \\
\hline 53. giraffa & giraffe & 578 & 836 & 1.93 & -0.96 & 117. treno & train & 525 & 951 & -0.04 & -0.44 \\
\hline 54. gonna & skirt & 526 & 880 & 0 & -0.76 & 118. tromba & trumpet & 509 & 981 & -0.63 & -0.3 \\
\hline 55. granchio & crab & 553 & 1,291 & 1 & 1.1 & 119. uomo & $\operatorname{man}$ & 487 & 1,110 & -1.43 & 0.28 \\
\hline 56. gufo & owl & 528 & 1,048 & 0.08 & 0 & 120. uovo & egg & 499 & 783 & -0.99 & -1.2 \\
\hline 57. imbuto & funnel & 532 & 938 & 0.2 & -0.5 & 121. valigia & suitcase & 532 & 855 & 0.23 & -0.87 \\
\hline 58. incudine & anvil & 592 & 1,384 & 2.45 & 1.53 & 122. vasca & bathtub & 510 & 1,076 & -0.6 & 0.13 \\
\hline 59. lampada & lamp & 493 & 1,042 & -1.23 & -0.03 & 123. verme & worm & 519 & 1,501 & -0.28 & 2.06 \\
\hline 60. libro & book & 504 & 770 & -0.8 & -1.26 & 124. volpe & fox & 486 & 1,183 & -1.47 & 0.61 \\
\hline 61. limone & lemon & 503 & 896 & -40.85 & -0.69 & 125. vulcano & volcano & 490 & 1,180 & -1.32 & 0.6 \\
\hline 62. lucchetto & lock & 523 & 1,166 & -0.13 & 0.54 & 126. zampa & paw & 527 & 1,573 & 0.01 & 2.38 \\
\hline 63. lucertola & lizard & 548 & 1,322 & 0.79 & 1.25 & 127. zanzara & mosquito & 549 & 1,428 & 0.85 & 1.73 \\
\hline 64. lumaca & snail & 502 & 1,020 & -0.91 & -0.13 & 128. zebra & zebra & 556 & 993 & 1.11 & -0.25 \\
\hline
\end{tabular}

